\title{
Guide for Authors
}

\section{Aims and Scope}

Molekul is a chemistry journal dedicated to covering research and development in the general chemistry including biochemistry, analytical chemistry, organic chemistry, inorganic chemistry and physical chemistry. The scope of the journal, but is not restricted to, the following areas:

- Theoretical chemistry study

- Environmental chemistry

- Material synthesis for energy and environmental applications

- Biomolecules isolation, purification and modification, including their applications

- Design, development and validation of analytical methods

\section{Type of paper}

Molekul welcomes full research papers, review articles (invitation only) and short communications. Full research papers should in general about $3000-5000$ words (1 2 printed pages) including figures and tables. Short communication should not exceed 2000 words (4 printed pages) with maximum 3 figures or tables.

\section{Publication fee}

Molekul is an Open Access journal, which is free to access and read on the Internet. The publisher guarantees that no reader will ever have to buy a subscription or pay-per-view fees to access the articles published in this journal. In order to cover the costs of providing and maintaining a publication infrastructure, managing the journals, and processing the manuscripts through peer-review and the editorial procedure, the journal uses a form of conditional submission fee referred to as Article Processing Charge (APC). Authors should pay a fee of 100 USD (foreigner) or Rp. 1.250 .000 (Indonesian) per processed paper only if the article is accepted to publish in this journal after peer-review process. There is free APC for foreign selected author opportunity, please contact the editor. This APC for online version only. If you need print version, please contact editors.

\section{Author statement letter}

Author should make the statement letter (can be download here) for originality and copyright transfer. Article preparation Paper should be prepare using common word processor software (e.g. Microsoft-Word ${ }^{\circledR}$ ), prepared in English language, type single column in Times New Roman font with size of 12 , space of 1.5 , page size of $A 4$, left margins of $3 \mathrm{~cm}$, top, right and bottom margins of $2.5 \mathrm{~cm}$.

\section{Article structure}

Article main heading should use bold font without numbering (example Abstract, Introduction). The subheading should use normal font, with numbering of 1,2, and 3 .

\section{Title}

Title information including:

1. Article title (maximum of 20 words), write both in English and Indonesian (for Indonesian author only).

2. Author name and affiliation, mark with superscript numbering 1,2, etc. of different author affiliations.

3. Corresponding author, mark with superscript asterisk "*", this would be used to mark the email address of the corresponding author, above the all author affiliation. 


\section{Abstract}

Abstract should state briefly the purpose of the research, methodology, main result and major conclusions. Abstract should not more than 200 words, write both in English and Indonesian (for Indonesian author only).

\section{Keywords}

Provide 3-5 word, alphabetically ordered, using the same language as abstract. Avoid using multiple concept and plural term (e.g. 'and', 'of'). These keywords will be used for indexing process.

\section{Introduction}

State the objectives of the work and provide an adequate background, avoiding a detailed literature survey or a summary of the results.

\section{Experimental Section}

Provide sufficient material and instrumentation mainly used in the work. Provide detail of the research method to allow the work to be reproduced. Methods already published should be indicated by a reference: only relevant modifications should be described.

\section{Results and Discussion}

Combination of results and discussion section used and should be clear and concise. This should explore the significance of the results of the work, not repeat them. Avoid extensive citations and discussion of published literature.

\section{Conclusions}

The main conclusions of the study should be presented in a short Conclusions section.

\section{Acknowledgement}

Supporting grant, collaboration or institution can be placed in this section.

\section{Appendices / Supplementary data}

Only necessary data can be included in the appendices (print version). Supporting data / information for online publication can be submitted in separate file of the manuscript.

\section{Math formulae}

Present simple formulae in the line of normal text where possible and use the solidus (/) instead of a horizontal line for small fractional terms, e.g., X/Y. In principle, variables are to be presented in italics. Powers of e are often more conveniently denoted by exp.

\section{Figure}

Figure artwork (digital photograph, chromatogram, scheme) should be clear with minimum resolution of $300 \mathrm{dpi}$. Artwork or scheme prepared using Ms Word, Ms Excel or Ms Powerpoint should be saved as tiff or JPG to avoid miss layout. Please put the figures inside the manuscript according to the related text, do not place the figures separately in the last of the manuscript. Figure caption Ensure each figure has a caption, place below the figure, center alignment, sentence case and avoid to use the uncommon abbreviation. Use the bold font of the figure caption (e.g Figure 1. Temperature effect on the amylase activity)

\section{Tabel}

Use horizontal border on the table header and last line, without vertical border. Place the table caption above the table. Footnote (if necessary) should be place below the table, with smaller font size of the table font. 


\section{References Type}

The references used should be minimum of $80 \%$ journal article and also minimum of $80 \%$ up to date reference (maximum of 10 years).

\section{Style}

The reference style used according to the APA (American Psychological Association) 6 th edition. It is highly recommended to use the reference manager to organize the references such as Zotero, Mendeley or Endnote.

The APA 6th Style can be found here:

Endnote Thomson Reuters: http://endnote.com/styles/APA\%206th.ens

Zotero: https://www.zotero.org/styles

Mendeley: http://csl.mendeley.com/

\section{Example:}

\section{In-text citations}

\section{Two authors}

Hermawan and Sulaeman (2010) reported ...

or

The use of chitosan as supporting material has been studied (Hermawan \& Sulaeman, 2010)

\section{Three to five authors}

First cite

Kernis, Cornell, Sun, Berry, \& Harlow (2013) explain....

or

(Kernis, Cornell, Sun, Berry, \& Harlow, 2013)

\section{Next cite}

Kernis et al. (1993) argued....

or

(Kernis et al., 1993)

\section{More than five authors}

Fatoni et al. (2014) reported ...

or

(Fatoni et al., 2001)

\section{Two or more reference in one sentence}

(Berndt, 2012; Harlow, 2010)

\section{Two or more references,}

In case of family names are the same, use initial of first name (E. Johnson, 2011; L. Johnson, 2008)

\section{List of references}

\section{Book}

Koolman, J., \& Röhm, K. H. (2005). Color atlas of biochemistry. Stuttgart; New York: Thieme.

\section{Journal Article}

Fatoni, A., Numnuam, A., Kanatharana, P., Limbut, W., Thammakhet, C., \& Thavarungkul, P. (2013). A highly stable oxygen-independent glucose biosensor based on a chitosan-albumin cryogel incorporated with carbon nanotubes and ferrocene. Sensors and Actuators B: Chemical, 185, 725-734. 


\section{Conference Proceeding}

Fatoni, A., Dwiasi, D. W., \& Hermawan, D. (2016). Alginate cryogel based glucose biosensor. In IOP Conference Series: Materials Science and Engineering (Vol. 107, No. 1, p. 012010). IOP Publishing. 


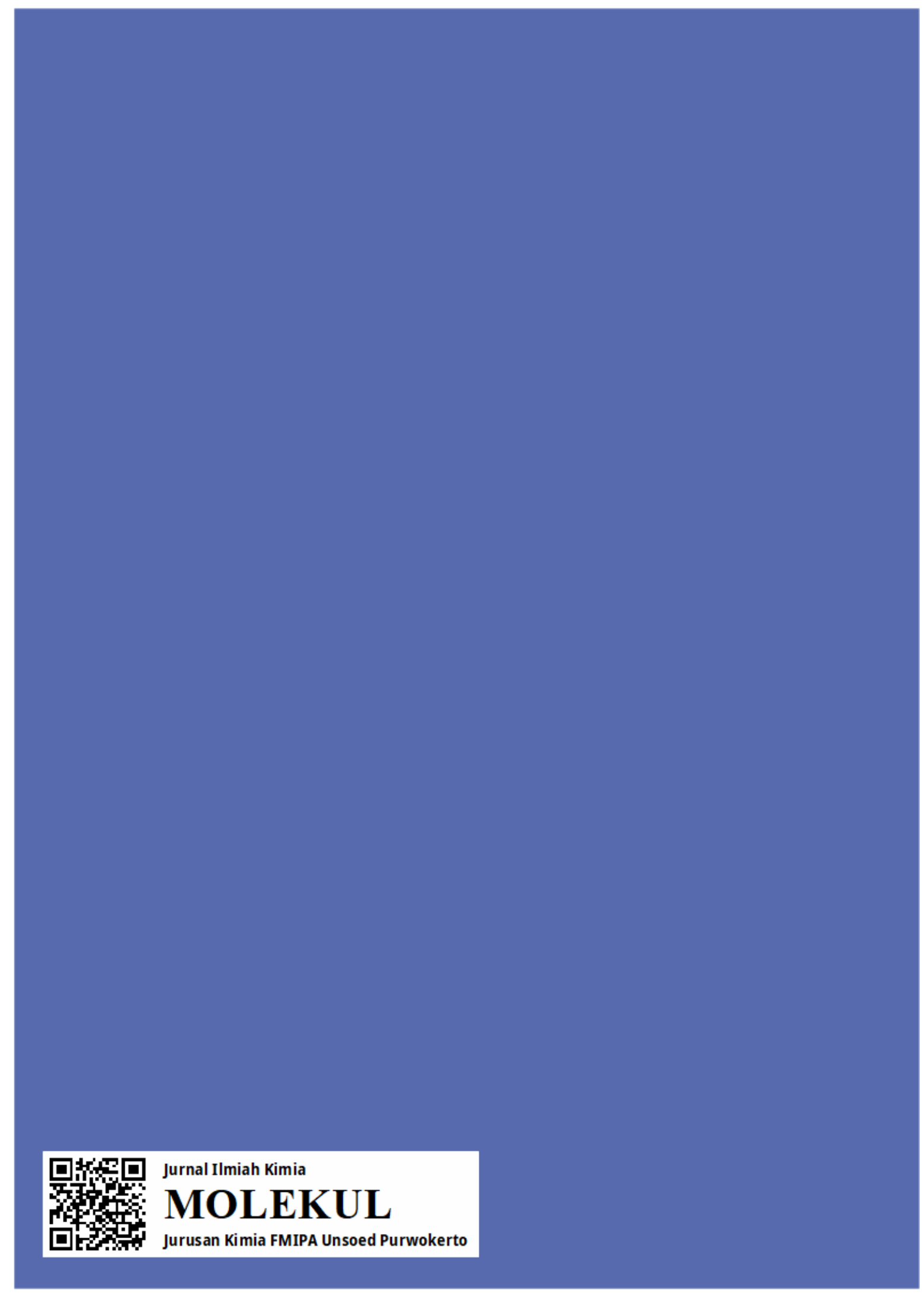

